\title{
Awareness and Knowledge of Smoking and Periodontitis Among Dental Patients
}

\author{
Sadikin AS ${ }^{1}$, Mansor $\mathrm{H}^{1}$, Saub $\mathrm{R}^{2}$, Vaithlingam $\mathrm{RD}^{3 *}$ \\ ${ }^{1}$ Department of Restorative Dentistry, Faculty of Dentistry, University of Malaya, Kuala Lumpur, Malaysia. \\ ${ }^{2}$ Department of Community Oral Health \&Clinical Prevention, Faculty of Dentistry, University of Malaya, Kuala \\ Lumpur, Malaysia. \\ ${ }^{3}$ Department of Restorative Dentistry, Faculty of Dentistry, University of Malaya, Kuala Lumpur, Malaysia.
}

\begin{abstract}
Objective: This study aimed to assess the awareness of periodontal disease and level of knowledge of the relationship between smoking and periodontal disease amongst subjects who were smokers verses non-smokers. Methods: A questionnaire looking at knowledge of respondents regarding gum disease and knowledge and awareness about oral impacts of smoking on periodontal disease was developed and pretested in Dental Faculty University of Malaya. Basic Periodontal Examination (BPE) index was used to assess periodontal status. Results: The questionnaire was answered by 130 subjects. Prevalence of smoking was $14.6 \%$. A total of $58.6 \%$ non-smokers and $57.9 \%$ smokers knew about periodontal disease. However, only $26.1 \%$ non-smokers and $10.5 \%$ smokers knew that the cause for periodontal disease was plaque. More non-smokers than smokers knew that smoking affected periodontal health $(80.2 \%$ and $68.4 \%$ respectively) $(p>0.05)$ and tooth mobility was an effect of smoking on periodontal health $(27.0 \%$ and $0 \%)(p<0.05)$. Regarding source of information on effect of smoking on periodontal health, $63.2 \%$ smokers and $63.1 \%$ non-smokers reported obtaining information through the mass media. However, only $31.6 \%$ smokers and $28.8 \%$ non-smokers were informed by their dentist. Conclusion: The awareness of periodontal disease and knowledge of the relationship between smoking and periodontal disease was low in this selected population of smokers and nonsmokers.
\end{abstract}

Keywords: Awareness, knowledge, periodontitis, smoking

\section{INTRODUCTION}

Periodontal disease is one of the two major dental diseases which have high prevalence rates worldwide, the other being caries. The World Health Organization (WHO) reported that $10-15 \%$ of the world population suffers from severe periodontal disease (1). Malaysians are also afflicted and more than $90 \%$ of our population has some form of periodontal disease while $18 \%$ of the population suffers from severe chronic periodontitis (2).

Chronic periodontitis is a multi-factorial disease with the dental biofilm as its initiator $(3,4)$. Smoking has been reported to be a major risk factor for the disease (5). Studies have shown that smokers have 
more periodontal disease regardless of oral hygiene (6). There is substantial body of evidence to support the observation that the more a patient smokes, the greater the degree of periodontal disease (7).

Based on the Global Adult Tobacco Survey (GATS) done amongst the Malaysian population in the year $2011,43.9 \%$ of men and $1.0 \%$ of women, currently smoked tobacco (http://www.moh.gov.my/ images/gallery/Report/GATS_Malaysia.pdf). The survey also found out that $93.5 \%$ of non-smoking adults and $88.1 \%$ of current smokers believed that smoking caused serious illness.

Al-Shammari et al (8) reported that the majority of dental patients in Kuwait were aware that smoking and oral health were related. A total of $89.5 \%$ of the subjects reported that tooth staining was the effect of smoking. The respondents also reported that smoking had an effect on periodontal health $(76.2 \%)$, oral cancer $(62.6 \%)$ and wound healing $(27.7 \%)$. Lung et al. (9) focused on the global understanding of patients' knowledge of the oral health effects of smoking in the United Kingdom. Based on their study, the results demonstrated that $78 \%$ of patients were aware that smoking had negative impacts on health.

Airila-Mansson et al. (10) conducted a study amongst an urban Swedish population of smokers and non-smokers where they compared their awareness of periodontal problems according to their periodontal status. For smokers, multivariate logistic regression analysis yielded an odds ratio (OR) of $3.21(95 \% \mathrm{Cl} 1.73,5.74)$ of self-reported periodontal disease, especially those who also reported having 'movable' teeth, and who were confirmed to have the disease. They found out that smokers were more aware of their periodontal status than non-smokers.

In the Malaysian context, only one known previous study has been conducted in this area looking at patient's awareness of smoking and periodontal disease amongst patients attending the Outpatient Clinic at the Dental Faculty, University Kebangsaan Malaysia (11). This study reported that only $36.7 \%$ of the patients were aware of periodontal disease as an oral impact of smoking. Based on the limited information available in this important area of smoking and periodontal disease, our study thus aims to assess the awareness of periodontal disease and compare the level of knowledge of the relationship between smoking and periodontal disease amongst subjects who are smokers verses non-smokers attending the Primary Care Unit, Faculty of Dentistry, University of Malaya.

\section{METHODOLOGY}

This comparative cross-sectional study was conducted on patients attending the Primary Care Unit, Faculty of Dentistry, University of Malaya. The examination period was between July to September 2014. Ethical approval was obtained from the Ethics Committee, Faculty of Dentistry, University of Malaya (DF RD 1408/0049) and the research has been conducted in full accordance with the World Medical Association Declaration of Helsinki. The nature of the study was explained to the subjects and written informed consent was obtained from all subjects who wished to participate in the study.

The inclusion criteria for the study was Malaysians who were 18 years and above. The study was conducted using anonymous, selfadministered questionnaires. The questionnaire consisted of close-ended questions which were available in both English and Bahasa Malaysia and was developed to cover the objectives of the study. Details of the respondent's age, gender, ethnicity, level of education, monthly income, dental visits, oral hygiene habits, presence of medical conditions (hypertension, diabetes, cardiovascular disease) as well as smoking status were obtained. The questionnaire was divided into two separate sections. The first section was on the knowledge of the respondents regarding gum disease. The second section was on the knowledge and awareness about oral effects of smoking on periodontal disease.

The questionnaire was pre-tested with a sample of 13 undergraduate students (from faculties other than Faculty of Dentistry) in the University of Malaya prior to the start of the survey. The questionnaire was found to have excellent reliability with a Pearson correlation score of 0.952. Questionnaire forms were then distributed to patients attending the Primary Care Unit and it was completed in the reception area prior to being examined by the clinicians in the Primary Care Unit. Once completed, the questionnaires were returned before the patient proceeded for treatment by the dentist at the Primary Care Unit.

\section{Clinical examination}

The periodontal status of all subjects was assessed using the Basic Periodontal Examination (BPE) index (http://www.bsperio.org.uk/publications/ downloads/39_143748_bpe2011.pdf). The WHO periodontal probe was used for this purpose. BPE index for all subjects was performed by the dentists from the Primary Dental Care Unit, Faculty of Dentistry, University of Malaya as part of their 
routine screening. Briefly, the mouth was divided into sextants and each sextant was examined only if there were 2 or more teeth present. Probing was done by walking the probe around all surfaces per tooth. The following codes were used: 0 , periodontal health; 1 , bleeding on probing; 2 , presence of calculus; 3 , pockets 4 to $5 \mathrm{~mm}$ depth; and 4, pockets more than $6 \mathrm{~mm}$. The highest BPE code for the mouth was used to determine if the subjects were periodontally healthy $(\mathrm{BPE}<3)$ or diseased $(\mathrm{BPE} \geq 3)$. The number of missing teeth for each patient (excluding the 8's) was also assessed.

\section{Data analysis}

The data was analyzed using the SPSS Version 12 for Windows. Comparisons between smoking status with sociodemographic characteristics, habits, knowledge of periodontal disease, periodontal health and knowledge and perception related to periodontal health and smoking were assessed using the Chi square test. Subsequently the periodontal status of subjects was compared using chi-square test. Level of significance was set at $p \leq 0.05$.

\section{RESULTS}

The sociodemographic characteristics and habits of the subjects according to their smoking status are shown in Table 1. Out of 130 patients, only a total of $14.6 \%$ of the respondents of the study were smokers. Among the smokers, $84.2 \%$ (16 subjects) were males and $15.8 \%$ (3 subjects) females. There was significantly more males who smoked as compared to females $(p=0.00)$. The Malay ethnic group $(68.4 \%)$ had the highest number of smokers as compared to other ethnic groups $(p=0.17)$. Among the smokers, $57.9 \%$ of them were within the age range of $18-34$ as compared to $52.3 \%$ of nonsmokers. The majority of participants (smokers and non-smokers) had completed tertiary education but had a monthly income of less than RM2000. With regards to medical conditions, diabetes $(p=0.86)$ and hypertension $(p=0.09)$ was more prevalent in the non-smoking group as compared to smokers. Around $60 \%$ of the smokers smoked 10 cigarettes or less per day. The majority of non-smokers visited the dentist 2 times or more per year as compared to smokers $(p=0.17)$. With regards to oral hygiene care, a higher number of smokers brushed their teeth more than twice per day as compared to non-smokers $(p=0.53)$. More smokers also reported performing inter-dental cleaning as compared to non-smokers $(p=0.05)$.

Table 1: Sociodemographic characteristics and habits amongst smokers and non-smokers.

\begin{tabular}{|c|c|c|c|c|}
\hline Variables & $\begin{array}{c}\text { Smoker }(\mathrm{N}=19) \\
\mathrm{n}(\%)\end{array}$ & $\begin{array}{c}\text { Non-smoker }(\mathrm{N}=111) \\
\mathrm{n}(\%)\end{array}$ & $\begin{array}{l}\text { Total } \\
\mathrm{n}(\%)\end{array}$ & $p$-value \\
\hline \multicolumn{5}{|l|}{ Age } \\
\hline $18-34$ & $11(57.9)$ & $58(52.3)$ & $69(53.1)$ & 0.72 \\
\hline $35-55$ & $6(31.6)$ & $33(29.7)$ & $39(30.0)$ & \\
\hline $56-80$ & $2(10.5)$ & $20(18.0)$ & $22(16.9)$ & \\
\hline \multicolumn{5}{|l|}{ Sex } \\
\hline Male & $16(84.2)$ & $39(35.1)$ & $55(42.3)$ & 0.00 \\
\hline Female & $3(15.8)$ & $72(64.9)$ & $75(57.7)$ & \\
\hline \multicolumn{5}{|l|}{ Ethnicity } \\
\hline Malay & $13(68.4)$ & $48(43.2)$ & $61(46.9)$ & 0.17 \\
\hline Chinese & $3(15.8)$ & $41(36.9)$ & $44(33.8)$ & \\
\hline Indian & $3(15.8)$ & $18(16.2)$ & $21(16.2)$ & \\
\hline Others & $0(0)$ & $4(3.6)$ & $4(3.1)$ & \\
\hline \multicolumn{5}{|l|}{ Level of education } \\
\hline Primary & $0(0)$ & $2(1.8)$ & $2(1.5)$ & 0.71 \\
\hline Secondary & $7(36.8)$ & $33(29.7)$ & $40(30.8)$ & \\
\hline Tertiary & $12(63.2)$ & $76(68.5)$ & $88(67.7)$ & \\
\hline \multicolumn{5}{|l|}{ Monthly income } \\
\hline$<$ RM2000 & $12(63.2)$ & $67(60.4)$ & $79(60.8)$ & 0.48 \\
\hline RM2000-RM5000 & $7(36.8)$ & $36(32.4)$ & $43(33.1)$ & \\
\hline
\end{tabular}




\begin{tabular}{|c|c|c|c|c|}
\hline Variables & $\begin{array}{c}\text { Smoker }(\mathrm{N}=19) \\
\mathrm{n}(\%)\end{array}$ & $\begin{array}{c}\text { Non-smoker }(\mathrm{N}=111) \\
\mathrm{n}(\%)\end{array}$ & $\begin{array}{l}\text { Total } \\
\mathrm{n}(\%)\end{array}$ & $p$-value \\
\hline >RM5000 & $0(0)$ & $8(7.2)$ & $8(6.2)$ & \\
\hline \multicolumn{5}{|c|}{ Presence of medical conditions } \\
\hline \multicolumn{5}{|l|}{ Diabetes } \\
\hline Yes & $1(5.3)$ & $7(6.3)$ & $8(6.2)$ & 0.86 \\
\hline No & $18(94.7)$ & $104(93.7)$ & $122(93.8)$ & \\
\hline \multicolumn{5}{|l|}{ Hypertension } \\
\hline Yes & $0(0)$ & $15(13.5)$ & $15(11.5)$ & 0.09 \\
\hline No & $19(100)$ & $96(86.5)$ & $115(88.5)$ & \\
\hline \multicolumn{5}{|c|}{ No. of cigarettes/day } \\
\hline$>10$ cigs/day & $7(36.8)$ & - & $7(36.8)$ & - \\
\hline$\leq 10$ cigs/day & $12(63.2)$ & - & $12(63.2)$ & \\
\hline \multicolumn{5}{|l|}{ Dental visits } \\
\hline$\geq 2$ times/year & $5(26.3)$ & $48(43.2)$ & $53(40.8)$ & 0.17 \\
\hline$<2$ times/ year & $14(73.7)$ & $63(56.8)$ & $77(59.2)$ & \\
\hline \multicolumn{5}{|c|}{ Tooth brushing habit } \\
\hline$<2$ time/day & $4(21.1)$ & $24(21.6)$ & $28(21.5)$ & 0.53 \\
\hline 2 time/ day & $7(36.8)$ & $54(48.6)$ & $61(46.9)$ & \\
\hline$>2$ times/day & $8(42.1)$ & $33(29.7)$ & $41(31.5)$ & \\
\hline \multicolumn{5}{|c|}{ Interdental brushing } \\
\hline Yes & $9(47.4)$ & $28(25.2)$ & $37(28.5)$ & 0.05 \\
\hline No & $10(52.6)$ & $83(74.8)$ & $93(71.5)$ & \\
\hline
\end{tabular}

p-value -chi-square test used for sociodemographic characteristics and habits

In these selected subjects, $57.9 \%$ of smokers smokers knew that dental plaque (biofilm) was the and $58.6 \%$ of non-smokers knew about gum disease. cause of periodontal disease (Table 2).

However only $10.5 \%$ of smokers and $26.1 \%$ non-

Table 2: Knowledge of periodontal disease amongst smokers and non-smokers.

\begin{tabular}{lcccc}
\hline Knowledge of periodontal disease & $\begin{array}{c}\text { Smoker } \\
\mathbf{( N = 1 9 )} \\
\mathbf{n}(\%)\end{array}$ & $\begin{array}{c}\text { Non-smoker } \\
\mathbf{( N = 1 1 1 )} \\
\mathbf{n}(\%)\end{array}$ & $\begin{array}{c}\text { Total } \\
\mathbf{n}(\%)\end{array}$ & p-value \\
\hline Know what gum disease is & $11(57.9)$ & $65(58.6)$ & $76(58.5)$ & 0.96 \\
\hline Yes & $8(42.1)$ & $46(41.4)$ & $54(41.5)$ & 0.22 \\
\hline No & & & \\
\hline Causes of gum disease & $4(21.1)$ & $9(8.1)$ & $13(10.0)$ \\
\hline Sweet food only & $2(10.5)$ & $29(26.1)$ & $31(23.8)$ & $13(10.0)$ \\
\hline Plaque only & $2(10.5)$ & $11(9.9)$ & $73(56.2)$ \\
\hline Sweet food and plaque & $11(57.9)$ & $62(55.9)$ & \\
\hline Don't know & & & \\
\hline
\end{tabular}

p-value -chi-square test 
Table 3 reports the knowledge and perceptions related to periodontal health and smoking between subjects who are smokers versus non-smokers. More non-smokers $(80.2 \%)$ than smokers $(68.4 \%)$ claimed that they were aware that smoking affected periodontal health $(p=0.35)$. Almost half of the smokers and non-smokers had the mistaken understanding that one of the effects of smoking on gum disease was that it caused an increase in gum bleeding. More non-smokers than smokers knew that tooth mobility was a negative effect of smoking on gum health $(p=0.01)$. On the other hand, very few smokers $(5.3 \%)$ and non-smokers $(20.7 \%)$ think that smoking can cause tooth loss.

Table 3: Knowledge and perception related to periodontal health and smoking between smokers and non-smokers

\begin{tabular}{|c|c|c|c|c|}
\hline & $\begin{array}{c}\text { Smoker } \\
(\mathrm{N}=19) \\
\mathrm{n}(\%)\end{array}$ & $\begin{array}{c}\text { Non-smoker } \\
\begin{array}{c}(\mathrm{N}=111) \\
\mathrm{n}(\%)\end{array}\end{array}$ & $\begin{array}{l}\text { Total } \\
\text { n(\%) }\end{array}$ & p-value \\
\hline \multicolumn{5}{|c|}{ Knowledge on the effect of smoking on periodontal disease } \\
\hline \multicolumn{5}{|c|}{ 1.Smoking has an effect on gum health status } \\
\hline Yes & $13(68.4)$ & $89(80.2)$ & $102(78.5)$ & 0.35 \\
\hline No & $0(0)$ & $2(1.8)$ & $2(1.5)$ & \\
\hline Not sure & $6(31.6)$ & $20(18.0)$ & $26(20.0)$ & \\
\hline \multicolumn{5}{|c|}{ 2. The effects of smoking on gum health. ${ }^{*}$} \\
\hline Gum swelling & $8(42.1)$ & $54(48.6)$ & $62(47.7)$ & 0.60 \\
\hline Gum bleeding & $9(47.4)$ & $59(53.2)$ & $68(52.3)$ & 0.64 \\
\hline Shaky/mobile teeth & $0(0)$ & $30(27.0)$ & $30(23.1)$ & 0.01 \\
\hline Tooth loss & $1(5.3)$ & $23(20.7)$ & $24(18.5)$ & 0.11 \\
\hline None of the above & $1(5.3)$ & $0(0)$ & $0(0)$ & $0(0)$ \\
\hline \multicolumn{5}{|c|}{$\begin{array}{l}\text { 3. Source of information regarding the effect of } \\
\text { smoking on gum health.* }\end{array}$} \\
\hline Dentist & $6(31.6)$ & $32(28.8)$ & $38(29.2)$ & 0.81 \\
\hline Doctor & $4(21.1)$ & $24(21.6)$ & $28(21.5)$ & 0.96 \\
\hline Mass media & $12(63.2)$ & $70(63.1)$ & $82(63.1)$ & 0.99 \\
\hline Books & $1(5.3)$ & $37(33.3)$ & $38(29.2)$ & 0.01 \\
\hline Health programs & $4(21.1)$ & $36(32.4)$ & $40(30.8)$ & 0.32 \\
\hline Family/friends & $9(47.4)$ & $29(26.1)$ & $38(29.2)$ & 0.06 \\
\hline
\end{tabular}

\section{Perceptions related to periodontal health and smoking}

1. Smokers should go for more frequent dental checkups compared to non-smokers.

\begin{tabular}{|c|c|c|c|c|}
\hline Yes & $17(89.5)$ & $101(91.0)$ & $118(90.8)$ & 0.83 \\
\hline No & $2(10.5)$ & $10(9.0)$ & $12(9.2)$ & \\
\hline \multicolumn{5}{|c|}{$\begin{array}{l}\text { 2. Smokers should have more frequent scaling than } \\
\text { non-smokers. }\end{array}$} \\
\hline Yes & $17(89.5)$ & $106(95.5)$ & $123(94.6)$ & 0.28 \\
\hline No & $2(10.5)$ & $5(4.5)$ & $7(5.4)$ & \\
\hline \multicolumn{5}{|c|}{ 3. Gum health would be better if you did not smoke. } \\
\hline Yes & $14(73.7)$ & - & $14(73.7)$ & - \\
\hline No & $0(0)$ & & $0(0)$ & \\
\hline Not sure & $5(26.3)$ & & $5(26.3)$ & \\
\hline
\end{tabular}

*more than 1 answer permitted

p-value -chi-square test used for sociodemographic characteristics and habits 
With regards to source of information regarding the effect of smoking on gum health, $63.2 \%$ smokers and $63.1 \%$ non-smokers reported that they obtained their information through the mass media. Besides the role of mass media, non-smokers were more likely to obtain this information from books as compared to smokers $(p=0.01)$ while smokers were more likely to obtain this information from family/ friends as compared to non-smokers ( $p>0.05)$. Only $31.6 \%$ of smokers were informed about the negative effects of smoking on their periodontal health by their dentists.

The majority of smokers and non-smokers perceived that smokers should go for more frequent dental check-ups (89.5\% and $91 \%$ respectively) and scaling $(89.5 \%$ and $95.5 \%$ respectively) as compared to non-smokers. The majority of smokers $(73.7 \%)$ also agreed that their gum health would be better if they did not smoke.

Two participants refused to perform intra-oral examination. Out of the remaining 109 participants, $30.5 \%$ of the total subjects suffered from periodontitis (BPE scores 3 and 4) (Table 4). There was no difference in the prevalence for periodontitis between the smokers and non-smokers. Among the smokers, only $26.3 \%$ suffered from periodontitis (BPE scores 3 and 4) (Table 4).

Table 4: Periodontal status of study subjects

\begin{tabular}{lcccc}
\hline Periodontal status & $\begin{array}{c}\text { Smoker } \\
(\mathbf{N}=19) \\
\mathbf{n}(\%)\end{array}$ & $\begin{array}{c}\text { Non-smoker } \\
(\mathbf{N}=109) \\
\mathbf{n}(\%)\end{array}$ & $\begin{array}{c}\text { Total } \\
(\mathbf{N}=128) \\
\mathbf{n}(\%)\end{array}$ & p-value \\
\hline $\begin{array}{l}\text { Healthy/ Gingivitis } \\
\text { (BPE 0, 1, 2) }\end{array}$ & $14(73.7)$ & $75(68.8)$ & $89(69.5)$ & 0.77 \\
$\begin{array}{l}\text { Periodontitis } \\
\text { (BPE 3,4) }\end{array}$ & $5(26.3)$ & $34(31.2)$ & $39(30.5)$ & \\
\hline
\end{tabular}

p-value -chi-square test

\section{DISCUSSION}

Only $14.6 \%$ of the respondents of this study were smokers. This is not reflective of the national population whereby it has been reported that $23.1 \%$ of Malaysians are smokers. This is also due to the fact that those who visit dentists are mostly those who are health conscious and practice good health habits.

In this study, about $50 \%$ of smokers and non-smokers knew about periodontal disease but only $10.5 \%$ of smokers and $26.1 \%$ non-smokers knew that dental plaque (biofilm) was the cause of periodontal disease. Similar findings were reported by Gholami et al. (12) where it was demonstrated that about $50 \%$ of the population in Teheran had poor knowledge of periodontal disease. Brodeur et al., (13) in their study on adult subjects in Quebec reported that only $26.4 \%$ of subjects with at least one tooth with a periodontal pocket of $6 \mathrm{~mm}$ or more knew that they required gum treatment. The reason for the low level of knowledge regarding periodontal disease may be attributed to the fact that generally oral health promotions conducted in the country are mainly geared towards caries prevention rather than periodontal health awareness. With the high prevalence of periodontitis reported in the Malaysian population (2), greater awareness with regards to periodontal disease should be created among Malaysians. This requires population-based preventive efforts that can address the underlying cause of the disease and should be jointly addressed by dental public health specialists, dental clinicians and dental professional organizations (14).

Despite claiming to be aware of the role of smoking on periodontal disease, the answers given to the questions regarding the actual effects of smoking on periodontal disease highlights a lack of awareness regarding the impact of smoking on periodontal disease in these subjects. Lung et al. (9) have also similarly reported that $78 \%$ of respondents from the United Kingdom reported to be aware that smoking affected oral health but only $6 \%$ knew the link between smoking and periodontal disease. The level of awareness between smoking and periodontal disease has also been reported to be extremely low 
among Nigerians (2.2\%) (15). In the current study, the reason for the level of awareness being higher than in these other studies may be due to the fact that the majority of these subjects have tertiary education.

With regards to source of information regarding the effect of smoking on gum health, slightly more than $60 \%$ smokers and non-smokers reported that they obtained their information through the mass media. This suggests the important role of the mass media in providing this information. Besides the role of mass media, non-smokers were more likely to obtain this information from books as compared to smokers $(p=0.01)$. Results from a Swedish research reported that information from media sources was more common among the younger group (Swedish adolescents aged 15-18) in their study sample (16). The current study also comprised a young population which may explain the major influence of the mass media in providing information to these subjects.

It is interesting to note that only $31.6 \%$ of smokers were informed about the negative effects of smoking on their periodontal health by their dentists. A previous study looking into the smoking cessation intervention activities of Malaysian government dentists reported that only $19.1 \%$ of dentists routinely recorded their patient's smoking status (17). With this small number of dentists actually taking a smoking history from their patients, it is not surprising that only a small percentage of dentists will then go on to inform their patients about the negative effects of smoking on periodontal health.

The majority of smokers and non-smokers perceived that smokers should go for more frequent dental check-ups and scaling as compared to nonsmokers. The majority of smokers also agreed that their gum health would be better if they did not smoke. These findings correlate with previous findings which reported that dental patients were aware that smoking had negative effects on periodontal health $(8,9)$.

A total of $30.5 \%$ of subjects suffered from periodontitis (BPE scores 3 and 4). These findings appear to be lower than the general prevalence of periodontitis in the country whereby $48.5 \%$ of the subjects have been reported to suffer from either moderate $(30.3 \%)$ or severe $(18.2 \%)$ periodontitis (2). For this study, individual BPE recording for all patients was obtained from the routine BPE screening performed by dentists in the Primary Care Unit who screen all new patients in the Faculty of Dentistry, University of Malaya. As there was no calibration of the BPE examination prior to commencing the study, hence the periodontal status of the respondent's may have been over or under diagnosed. To overcome this limitation, a future study should take into consideration the calibration of BPE recordings amongst all clinical examiners prior to the clinical examination of study subjects.

Among the smokers, only $26.3 \%$ suffered from periodontitis (BPE scores 3 and 4) (Table 4). This is in contrast to findings from other studies which have reported a higher prevalence for periodontitis amongst smokers as compared to non-smokers (18, 19). The reason for this finding could have been due to the small sample size of subjects and also due to the fact that the majority $(63.2 \%)$ of smokers in this study only smoked less than 10 cigarettes per day, as the effect of smoking on periodontal tissue depends on the daily dose and duration of smoking $(20,21)$.

The findings from this study suggest that the level of knowledge and awareness with regards to periodontal disease and its relationship to smoking remains low amongst patients who are smokers and non-smokers in the Faculty of Dentistry, University of Malaya. This finding demonstrates that the recommendation by the International Dental Federation (FDI) to its member associations and oral health professionals to take action in reducing tobacco use amongst the population has still not been realized in Malaysia (22). It has been recognized that dental health professionals play an important role in educating and informing their patients about the health risk of smoking and supporting them in cessation of this habit (23). Malaysian dental professionals should therefore perform smoking cessation interventions as an important part of oral health, and in particular periodontitis management in the dental setting.

\section{CONCLUSION}

The awareness of periodontal disease and knowledge of the relationship between smoking and periodontal disease was low in dental patients regardless of their smoking status. Thus, attending dentists must play their role in educating their patients about gum health. Mass media is an important source in obtaining information about effects of smoking on periodontal health. It is recommended that more information about this effect is put in the mass media. 


\section{REFERENCES}

1. Petersen PE, Ogawa H. Strengthening the prevention of periodontal disease: the $\mathrm{WHO}$ approach. J Periodontol 2005: 76: 2187-2193.

2. Oral Health Division, Ministry of Health Malaysia. National Oral Health Survey of Adults 2010 (NOHSA 2010): Initial findings (Unweighted data).

3. Kinane DF, Chestnutt IG. Relationship of diabetes to periodontitis. Curr Opin Periodontol 1997; 4: 29-34.

4. Loe H, Theilade E, Jensen SB. Experimental gingivitis in man. J Periodontol 1965; 36: 17787.

5. Brothwell DJ. Should the smoking cessation products be promoted by dental offices? An evidence based report. J Can Dent Assoc 2001; 67: 149-155.

6. Bergstrom J, Preber H. Tobacco use as a risk factor. J Periodontol 1994; 65: 545-550.

7. Heasman L, Stacey F, Preshaw PM, McCracken G, Hepburn S, Heasman PA. The effect of smoking on periodontal treatment response: a review of clinical evidence. J Clin Periodontol 2006; 33: 241-253.

8. Al-Shammari KF, Moussa MA, Al-Ansari JM, Al-Duwairy YS, Honkala EJ. Dental patient awareness of smoking effects on oral health: Comparison of smokers and non-smokers. J Dent 2006; 34: 173-178.

9. Lung ZH, Kelleher MG, Porter RW, Gonzalez J, Lung RF. Poor patient awareness of the relationship between smoking and periodontal diseases. Br Dent J 2005; 199: 731-737.

10. Airila-Mansson S, Soder B, Jin LJ, Soder PO, Klinge B. Self-reporting of periodontal diseases and clinical assessment outcome in a Swedish urban population of smokers and non-smokers. Acta Odontol Scand 2004; 62: 111-115.

11. Baharin B, Chien $Y L$, Koh KS. A Preliminary Study on Patient Awareness of Smoking and Periodontal Disease at Universiti Kebangsaan Malaysia Dental Faculty. Malays $\mathrm{J}$ of Med Sci Suppl 2007; 24: 256-256.

12. Gholami M, Pakdaman A, Montazeri A, Jafari A, Virtanen Jl. Assessment of periodontal knowledge following a mass media oral health promotion campaign: a population-based study. BMC Oral Health 2014; 5: 14:31.

13. Brodeur JM, Payette M, Beniger M, Charbonneau A, Olivier M, Chabot D. Periodontal diseases among Quebec adults aged 35 to 44 years. J Can Dent Assoc 2001; 67: 34.

14. Watt RG, Petersen PE. Periodontal health through public health--the case for oral health promotion. Periodontol 2000 2012; 60: 147-55.

15. Solomon ON, Patricia OA, Modupe OA, Osagie $\mathrm{A}$, Adeleke O. Awareness of link between smoking and periodontal disease in Nigeria: a comparative study. Res Rep Trop Med 2010; 1: 45-51.

16. Lundborg, P. Smoking, information sources, and risk perceptions-new results on Swedish data. Discussion Paper 2006-035.

17. Vaithilingam RD, Mohd Noor NM, Mustafa R, Taiyeb Ali TB. Practices and beliefs among Malaysian dentists and periodontists towards smoking cessation intervention. Sains Malaysiana 2012; 41: 929 - 935.

18. Johnson GK, Hill M. Cigarette smoking and the periodontal patient. J Periodontol 2004; 75:196-209.

19. Bergstrom J. Influence of tobacco smoking on periodontal bone height. Long-termobservations and a hypothesis. J Clin Periodontol 2004; 31: 260-266.

20. Haber J, Kent RL. Cigarette smoking in periodontal practice. J Periodontol 1992; 63:100-106.

21. Martinez-Canut P, Lorca A, Magan R. Smoking and periodontal disease severity. J Clin Periodontol 1995; 22: 743-749.

22. Johnson NW, Bain CA. Tobacco and oral disease. EU-working group on tobacco and oral health. Br Dent J 2000; 189: 200-206.

23. Khalaf $F$, Mohamed A, Jassem M, Yousif $S$, Eino J. Dental patient awareness of smoking effects on oral health: Comparison of smokers and nonsmokers. J Dent 2006; 34: 173-178.

\section{*Corresponding author:}

\author{
Dr. Rathna Devi Vaithilingam \\ Department of Restorative Dentistry, \\ Faculty of Dentistry, \\ University of Malaya, \\ Kuala Lumpur, Malaysia \\ Email: rathna@um.edu.my
}

